\title{
The impact of a structured intensive modular training in the learning curve of robot assisted radical prostatectomy
}

\author{
Riccardo Schiavina ${ }^{1,2}$, Marco Borghesi ${ }^{1,2}$, Hussam Dababneh ${ }^{1}$, Martina Sofia Rossi ${ }^{1}$, \\ Cristian Vincenzo Pultrone ${ }^{1,2}$, Valerio Vagnoni ${ }^{1}$, Francesco Chessa ${ }^{1}$, Lorenzo Bianchi ${ }^{1}$, \\ Angelo Porreca ${ }^{3}$, Alexandre Mottrie ${ }^{4}$, Eugenio Brunocilla ${ }^{1,2}$ \\ ${ }^{1}$ University of Bologna, S. Orsola-Malpighi Hospital, Dept. of Urology, Bologna, Italy; \\ ${ }^{2}$ Department of Experimental, Diagnostic and Specialty Medicine (DIMES), Cardio-Nephro-Thoracic Sciences Doctorate, \\ University of Bologna, Bologna, Italy; \\ ${ }^{3}$ Policlinico Di Abano, Dept. of Urology, Abano Terme, Italy; \\ ${ }^{4}$ OLV Robotic Surgery Institute, Aalst, Belgium.
}

\begin{abstract}
Summary Aim: The success of Robot Assisted
Laparoscopic Prostatectomy (RALP) is mainly due to his relatively short learning curve. Twenty cases are needed to reach a "4 hours-proficiency". However, to achieve optimal functional outcomes such as urinary continence and potency recovery may require more experience. We aim to report the perioperative and early functional outcomes of patients undergoing RALP, after a structured modular training program.

Methods: A surgeon with no previous laparoscopic or robotic experience attained a 3 month modular training including: a) e-learning; b) assistance and training to the operating table; c) dry console training; d) step by step in vivo modular training performing 40 surgical steps in increasing difficulty, under the supervision of an experienced mentor. Demographics, intraoperative and postoperative functional outcomes were recorded after his first 120 procedures, considering four groups of 30 cases.

Results: All procedures were completed successfully without conversion to open approach. Overall $19(15 \%)$ post operative complications were observed and $84 \%$ were graded as minor (Clavien I-II). Overall operative time and console time gradually decreased during the learning curve, with statistical significance in favour of Group 4. The overall continence rate at 1 and 3 months was $74 \%$ and $87 \%$ respectively with a significant improvement in continence rate throughout the four groups $(p=0.04)$. Considering those patients submitted to nerve-sparing procedure we found a significant increase in potency recovery over the four groups $(p=0.04)$ with the higher potency recovery rate up to $80 \%$ in the last 30 cases.

Conclusions: Optimal perioperative and functional outcomes have been attained since early phase of the learning curve after an intensive structured modular training and less than 100 consecutive procedures seem needed in order to achieve optimal urinary continence and erectile function recovery.
\end{abstract}

KEY WORDS: Training; Robot assisted radical prostatectomy.

Submitted 18 September 2017; Accepted 23 September 2017

\section{INTRODUCTION}

Prostate cancer is the second most common cancer among men, and represents the fifth cause of cancer death in men worldwide (1). Radical prostatectomy (RP) represents the standard surgical treatment for clinically localized prostate cancer (2). Traditionally this procedure was performed with a retropubic open approach retropubic radical prostatectomy (RRP) (3), with the cost of long hospitalization, the need of additional pain medication and significant blood loss. With the aim to reduce morbidity, hospitalization and to improve functional outcomes, minimally invasive approaches including laparoscopic radical prostatectomy (LRP) and robot assisted laparoscopic prostatectomy (RALP) have been increasingly adopted as alternative to open surgery. In the last two decades RALP has gained more popularity and now is a mainstay of treatment for prostate cancer, with functional and oncological outcomes comparable or even better than RRP and LRP (4-6). One of the main reason for the great diffusion of RALP is the short learning curve: contrarily to LRP, where the learning curve is very steep, those surgeons approaching to RALP were able to perform minimally invasive prostatectomy with optimal results even in the early phase of their learning curve, even with limited laparoscopic skills (7). Several studies estimated that few cases (25-40) are needed to shorten operative time, reduce the intraoperative blood loss and complications, thus rapidly achieving proficiency in $\operatorname{RALP}(8,9)$. However, to reach adequate functional outcomes and optimal oncological results in terms of negative surgical margins, more and more cases are needed and the learning curve is more steep for these outcomes (10).

As previous described by other authors $(11,12)$, RALP can count two different pattern of learning curves. The "basic learning curve" is centered on operative outcomes, in which 25-50 cases are needed to reach an operative time plateau of 200-240 minutes with low complication rate, even in more challenging patients (11).

The "advanced learning curve" is centered on patients outcomes, in which 100, 200 and 300 cases are needed to achieve satisfactory outcomes for the surgeon in terms of continence, potency recovery and positive surgical margins rates, respectively (11). 
Several parameters can influence the learning curve, such as the type of training program attended, the surgeon-related skills and personal experience in other procedures. A multitude of training programs exists in robotic surgery. Recently, some structured modular training programs were developed with the aim to simplify the learning curve in robotic surgery $(13,14)$ : these trainings allowed surgeons with no robotic experience to perform RARP independently, safely, and effectively with subsequent improvement over time but the "advanced" end-points were not evaluable (15).

The aim of the present study is to report the early perioperative and functional outcomes after the first 120 cases with a structured intensive modular training program applied to single surgeon with no previous laparoscopic or robotic experience.

\section{PATIENTS AND METHOdS}

Between January 2015 and May 2016, 120 consecutive patients underwent RALP for prostate cancer performed by a single surgeon with some experience in RRP (about 50 cases performed as first surgeon) but no laparoscopic skills (no cases of LRP). All the procedures were performed after attending a structured modular training. RALP was performed transperitoneally using the Da Vinci Xi surgical system (Intuitive Surgical, Inc., Sunnyvale, CA, USA) as previously described in details (16). Routine pelvic lymph node dissection (PLND) at time of RALP was performed in presence of high risk PCa and intermediate risk PCa with estimated risk for positive lymph nodes > $5 \%$ (2). Nerve sparing procedure was performed according to the D'Amico risk group classification and preoperative multi-parametric magnetic resonance imaging (mpMRI) results in patients with preoperative International Index of Erectile Function score (IIEF) $>21$.

Clinical, perioperative and pathological data were recorded. Sexual functional evaluation with IIEF2 and continence rate was assessed before and after surgery (13 months). Postoperative complications were graded according to the Clavien Dindo Classification (17) and grouped as minor (grade 1-2) or major (grade 3-5) complication.

\section{Postoperative follow-up and data collection}

The clinical and radiological assessment during follow-up included cystogram before catheter removal when deemed necessary, physical examination and abdominal ultrasound 1 month after surgery in those submitted to PLND. At 1 and 3 months after surgery we evaluated continence recovery, defined as the need for no pad or one safety-pad per day and potency, defined as erection adequate for penetration or postoperative IIEF score $>21$.

The study was in line with the local institutional ethical committees (approval code STUD-OF by the S. OrsolaMalpighi Hospital, IRB September 11, 2012). All patients provided informed consent for anonymous publication of data.

\section{Modular training}

Before performing the first RALP of the study, the surgeon attained a 3 month modular training which includ- ing: a) e-learning consisting of theoretical lessons and video sessions concerning the different steps of the procedure; b) dry lab performing procedures on ex-vivo models and wet lab c) assistance at the operating table; d) console training with simulator; e) step-by step in vivo modular training in which the main surgeon, supervised by an expert mentor (A.P.), performing 40 surgical steps in increasing difficulty (14). The training was performed at a training Center in Belgium (ORSI training center) and at a robotic center in the North of Italy (Abano terme Hospital, Padua).

\section{Statistical analysis}

Means and standard deviation, medians and interquartile ranges were reported for continuous variables. Frequencies and proportions were reported for categorical variables. The Mann-Whitney U Test and chi-square tests were used to compare the statistical significance of differences in medians and proportions, respectively.

Primary outcomes where the overall operative time (OT) and console time, positive surgical margins (PSM), complication rates, urinary continence recovery and potency recovery during the learning curve. To assess the learning curve, patients were divided into 4 groups of 30 consecutive RALP: Group 1 from case 1 to case 30; Group 2 from case 31 to case 60; Group 3 from case 61 to case 90; and Group 4 from case 91 to case 120. Kaplan-Meier analyses were used to predict early urinary continence and erectile function recovery after surgery. Statistical analyses were conducted using SPSS version 17.0 (IBM Corp, Armonk, NY). Two-tailed P values less than 0.05 were considered statistically significant.

\section{RESULTS}

Patient's demographics and preoperative clinical characteristics are summarized in Table 1. All procedures were completed successfully without conversion to open approach. Overall, 84 (70\%) patients were potent (IIEF score $>21)$ at time of surgery and median baseline IIEF-5 score was 21 . All patients were continent before surgery. No statistical differences were found between the four groups.

Table 2 depicts intraoperative and postoperative outcomes stratified according to the four groups: median OT and console time was 275 and 220 min and gradually decreased during the learning curve, with statistical significance in favour of Group 4. Median estimated blood loss (EBL) was $470 \mathrm{~mL}$, median hospital stay was 3 day; grade 1-2 postoperative complications were 16 (12\%) and grade 3-4 postoperative complications were 3 (2\%); the four groups were comparable in terms of estimated blood loss, intraoperative complications, PSM and days of hospitalization. A detailed report of intraoperative and postoperative complications stratified according to the study groups is reported in Table 3. Management of intraoperative complications included intra operative repair of bladder injury (2 cases), bowel injury (1 case) and iliac vein injury ( 1 case). No intraoperative complications occurred in group 4. Overall 19 (15\%) post operative complications were reported in 19 patients. Most of the adverse events (84\%) were graded as minor (Clavien 
Table 1.

Demographic and clinical characteristics in overall population and after stratifying patients according to four consecutive groups.

\begin{tabular}{|c|c|c|c|c|c|c|}
\hline Variables & Overall $(n=120)$ & Group $1(n=30)$ & Group $2(n=30)$ & Group $3(n=30)$ & Group $4(n=30)$ & $\mathbf{P}$ \\
\hline \multicolumn{7}{|l|}{ Age } \\
\hline Mean \pm SD & $64.5 \pm 6.5$ & $65.2 \pm 7.2$ & $63 \pm 5.8$ & $66 \pm 5.7$ & $62.3 \pm 6.8$ & \multirow[t]{2}{*}{0.3} \\
\hline Median (IQR) & $65(60-69)$ & $67(60-73)$ & $65(57-68)$ & $67(63-71)$ & $63(59-68)$ & \\
\hline \multicolumn{7}{|l|}{ BMI } \\
\hline Mean \pm SD & $26.3 \pm 4.4$ & $25.3 \pm 5.8$ & $26 \pm 3.2$ & $27 \pm 4.4$ & $26 \pm 3.8$ & \multirow[t]{2}{*}{0.4} \\
\hline Median (IQR) & $25.8(23.6-29.4)$ & $25.7(22.5-29.4)$ & $26.3(23.9-28.9)$ & $27.4(24.8-30)$ & $24.7(23.1-29.1)$ & \\
\hline \multicolumn{7}{|c|}{ Baseline PSA value $\mathrm{ng} / \mathrm{ml}$} \\
\hline Mean \pm SD & $7.8 \pm 5$ & $8.2 \pm 5.5$ & $13 \pm 5.7$ & $7.16 \pm 4.8$ & $7.8 \pm 4.1$ & \multirow[t]{2}{*}{0.3} \\
\hline Median (IQR) & $6.3(5.0-8.7)$ & $6.0(4.9-9.5)$ & $6.6(5-8.4)$ & $6.2(4.9-9.6)$ & $6.2(5-8.9)$ & \\
\hline \multicolumn{7}{|c|}{ Charlson Index $\mathbf{n}(\%)$} \\
\hline 0 & $103(85.8)$ & $27(90)$ & $27(90)$ & $25(83.3)$ & $24(80)$ & \multirow[t]{2}{*}{0.6} \\
\hline$\geq 1$ & $17(14.2)$ & $3(10)$ & $3(10)$ & $5(16.7)$ & $6(20)$ & \\
\hline \multicolumn{7}{|c|}{ Clinical Stage $\mathbf{n}(\%)$} \\
\hline $\mathrm{T} 1$ & $45(37.5)$ & $9(30)$ & $12(40)$ & $7(23.3)$ & $17(56.7)$ & \multirow[t]{3}{*}{0.1} \\
\hline T2 & $73(60.8)$ & $20(66.7)$ & $18(60)$ & $22(73.3)$ & $13(43.3)$ & \\
\hline \multirow{2}{*}{\multicolumn{7}{|c|}{ Gleason Score at biopsy n (\%) }} \\
\hline & & & & & & \\
\hline 6 & $18(15.0)$ & $5(16.7)$ & $4(13.3)$ & $5(16.7)$ & $4(13.3)$ & \multirow[t]{3}{*}{0.9} \\
\hline 7 & $75(62.5)$ & $19(63.3)$ & $20(66.7)$ & $16(53.3)$ & $20(66.7)$ & \\
\hline $8-10$ & $27(22.5)$ & $6(20)$ & $6(20)$ & $9(30)$ & $6(20)$ & \\
\hline \multicolumn{7}{|c|}{ D'Amico Risk group n (\%) } \\
\hline Low & $20(16)$ & $6(20)$ & $6(20)$ & $5(17)$ & $3(10)$ & \multirow[t]{3}{*}{0.3} \\
\hline Intermediate & $67(56)$ & $16(53)$ & $17(57)$ & $13(45)$ & $21(70)$ & \\
\hline High & $33(28)$ & $8(27)$ & $7(23)$ & $12(38)$ & $6(20)$ & \\
\hline \multicolumn{7}{|c|}{ Baseline IIEF-5 score } \\
\hline Mean \pm SD & $19 \pm 6$ & $19 \pm 5.4$ & $17 \pm 7.1$ & $19 \pm 5.2$ & $19 \pm 6$ & \multirow[t]{2}{*}{0.4} \\
\hline Median (IQR) & $21(15-23)$ & $217(14-23)$ & $21(10-22)$ & $22(18-23)$ & $22(21-23)$ & \\
\hline
\end{tabular}

Table 2.

Intraoperative and postoperative outcomes in overall population and after stratifying patients according to four consecutive groups.

\begin{tabular}{|c|c|c|c|c|c|c|}
\hline Variables & Overall $(n=120)$ & Group $1(n=30)$ & Group $2(n=30)$ & Group $3(n=30)$ & Group $4(n=30)$ & $\mathbf{P}$ \\
\hline \multicolumn{6}{|l|}{ Operative time ( $\mathrm{min})$} & \multirow[t]{2}{*}{$<0.001$} \\
\hline $\begin{array}{l}\text { Mean } \pm \text { SD } \\
\text { Median (IQR) }\end{array}$ & $\begin{array}{c}280 \pm 99 \\
275(245-315)\end{array}$ & $\begin{array}{c}353 \pm 167 \\
330(294-352)\end{array}$ & $\begin{array}{c}300 \pm 52 \\
304(253-336)\end{array}$ & $\begin{array}{c}243 \pm 33 \\
245(225-270)\end{array}$ & $221 \pm 28.6$ & \\
\hline \multicolumn{6}{|l|}{ Console time (min) } & \multirow[t]{2}{*}{0.01} \\
\hline $\begin{array}{l}\text { Mean } \pm \text { SD } \\
\text { Median (IOR) }\end{array}$ & $\begin{array}{c}220 \pm 47 \\
220(185-270)\end{array}$ & $\begin{array}{c}260 \pm 46 \\
270(220-300)\end{array}$ & $\begin{array}{c}237 \pm 52 \\
237(253-336)\end{array}$ & $\begin{array}{c}200 \pm 33 \\
197(179-225)\end{array}$ & $\begin{array}{c}177 \pm 28.4 \\
180(155-200)\end{array}$ & \\
\hline \multicolumn{6}{|l|}{ Estimated Blood loss (mL) } & \multirow[t]{2}{*}{0.2} \\
\hline $\begin{array}{l}\text { Mean } \pm \text { SD } \\
\text { Median (IQR) }\end{array}$ & $\begin{array}{c}460(160) \\
470(350-600)\end{array}$ & $\begin{array}{c}443(178) \\
485(300-600)\end{array}$ & $\begin{array}{c}362(108) \\
350(300-410)\end{array}$ & $\begin{array}{c}450(146) \\
430(365-525)\end{array}$ & $\begin{array}{c}534(160) \\
500(437-600)\end{array}$ & \\
\hline \multicolumn{6}{|l|}{ Nerve sparing procedure, $\mathrm{n}(\%)$} & \multirow[t]{3}{*}{0.3} \\
\hline $\begin{array}{l}\text { Not performed } \\
\text { Monolateral }\end{array}$ & $\begin{array}{l}38(32.5) \\
22(18.3)\end{array}$ & $\begin{array}{l}14(47) \\
5(16)\end{array}$ & $\begin{array}{l}8(26) \\
8(26)\end{array}$ & $\begin{array}{l}10(33) \\
5(16)\end{array}$ & $\begin{array}{l}6(21) \\
4(13)\end{array}$ & \\
\hline Bilateral & $60(49.2)$ & $11(37)$ & $14(48)$ & $15(50)$ & $20(66)$ & \\
\hline \multicolumn{6}{|l|}{ Lymphadenectomy, n (\%) } & \multirow[t]{2}{*}{0.393} \\
\hline Performed & $70(58)$ & $17(56)$ & $16(53)$ & $19(63)$ & $14(46)$ & \\
\hline Intraoperative complications, $\mathbf{n}(\%)$ & $5(5)$ & $2(7)$ & $2(7)$ & $1(3)$ & $0 /$ & \multirow{5}{*}{$\begin{array}{l}0.4 \\
0.5\end{array}$} \\
\hline \multicolumn{6}{|l|}{ Pathologic stage, $n(\%)$} & \\
\hline $\mathrm{T} 2$ & $83(68)$ & $18(60)$ & $20(66)$ & $21(73)$ & $23(77)$ & \\
\hline ТЗа & $32(27)$ & $12(40)$ & $8(27)$ & $7(20)$ & $6(20)$ & \\
\hline \multirow{2}{*}{\multicolumn{6}{|c|}{ Pathologic Gleason Score, n (\%) }} & \\
\hline & & & & & & \multirow[t]{4}{*}{0.4} \\
\hline 6 & $14(11)$ & $3(10)$ & $2(7)$ & $7(22)$ & $2(7)$ & \\
\hline 7 & $76(63)$ & $19(63)$ & $23(78)$ & $14(48)$ & $20(66)$ & \\
\hline $8-10$ & $30(26)$ & $8(27)$ & $5(15)$ & $9(30)$ & $8(27)$ & \\
\hline \multirow{2}{*}{$\begin{array}{l}\text { Positive surgical margins (PSM), } n \text { (\%) } \\
\text { PSM according to pathologic stage, } n \text { (\%) }\end{array}$} & $24(20)$ & $8(26)$ & $10(33)$ & $4(13)$ & $2(6)$ & \multirow{4}{*}{$\begin{array}{l}0.3 \\
0.5\end{array}$} \\
\hline & $8(10)$ & $3(16)$ & $3(15)$ & 1 (5) & $1(4)$ & \\
\hline pT3a $(n=32)$ & $13(40)$ & $5(41)$ & $\begin{array}{l}3(15) \\
6(75)\end{array}$ & $\begin{array}{l}1(0) \\
1(14)\end{array}$ & $\begin{array}{l}1(4) \\
1(16)\end{array}$ & \\
\hline pT3b $(n=5)$ & $3(60)$ & -8 & $1(50)$ & $2(100)$ & 0 & \\
\hline \multicolumn{6}{|l|}{ Hospital stay (days) } & \multirow[t]{2}{*}{0.3} \\
\hline Median (IQR) & $3.5(3-4)$ & $3(3-4)$ & $4(3-4)$ & $3(3-4.5)$ & $3(3-4)$ & \\
\hline \multicolumn{6}{|l|}{ Post-operative complications n (\%) } & \multirow[t]{3}{*}{0.6} \\
\hline Clavien $1-2$ & $16(12)$ & $9(30)$ & $2(3)$ & $2(6)$ & $3(10)$ & \\
\hline Clavien 3-4 & $3(2)$ & - & $2(10)$ & 0 & $1(3)$ & \\
\hline \multicolumn{6}{|l|}{ Post operative IIEF-5 Score** } & \multirow[t]{2}{*}{0.04} \\
\hline $\begin{array}{l}\text { Mean } \pm \text { SD } \\
\text { Median (IOR) }\end{array}$ & $\begin{array}{c}13(8) \\
18(6-21)\end{array}$ & $\begin{array}{c}12(7) \\
14(6-18)\end{array}$ & $\begin{array}{c}11(8) \\
14(4-19)\end{array}$ & $\begin{array}{c}12(9) \\
18(0-20)\end{array}$ & $\begin{array}{c}18(8) \\
21(18-25)\end{array}$ & \\
\hline \multirow{2}{*}{$\begin{array}{l}\text { Post operative continence recovery } \\
\text { Continent }, n(\%) \\
\text { Not continent***, } n(\%)\end{array}$} & & & & & & \multirow[t]{2}{*}{$<0.001$} \\
\hline & $\begin{array}{l}103(86) \\
17(14)\end{array}$ & $\begin{array}{l}23(76) \\
7(24)\end{array}$ & $\begin{array}{l}21(70) \\
9(30)\end{array}$ & $\begin{array}{c}29(99) \\
1(1)\end{array}$ & $\begin{array}{c}30(100) \\
0\end{array}$ & \\
\hline
\end{tabular}


Table 3.

Incidence and type of intraoperative and post-operative complications according to Dindo-Clavien classification in overall population and after stratifying patients according to four consecutive groups.

\begin{tabular}{|c|c|c|c|c|c|c|c|}
\hline \multicolumn{8}{|c|}{ Intraoperative complications } \\
\hline Type & Overall, n 5 (\%) & Group 1 & Group 2 & Group 3 & Group 4 & Treatment & Dindo-Clavien grade \\
\hline Ureteral injury & $1(0.8)$ & $1(3)$ & - & & - & Intraoperative ureteral stent placement & n.v. \\
\hline Bladder injury & $2(1.6)$ & - & $1(3)$ & $1(3)$ & - & Intraoperative surgical reparation & n.v. \\
\hline Bowel injury & $1(1.6)$ & $1(3)$ & - & & - & Intraoperative surgical reparation & n.v. \\
\hline Iliac vein injury & $1(1.6)$ & - & $1(3)$ & - & - & Intraoperative surgical reparation & n.v. \\
\hline \multicolumn{8}{|c|}{ Post-operative complications } \\
\hline Type & Overall, n 19 (\%) & Group 1 & Group 2 & Group 3 & Group 4 & Treatment & Dindo-Clavien grade \\
\hline Adductor muscle deficit & $1(1)$ & $1(3)$ & - & - & - & Medical therapy & 1 \\
\hline Fever & $5(4)$ & $4(13)$ & - & $1(3)$ & - & Medical therapy & 2 \\
\hline Lymphocele with fever & $4(3)$ & $1(3)$ & $1(3)$ & $1(3)$ & $1(3)$ & Medical therapy & 2 \\
\hline Anemia & $6(5)$ & $3(10)$ & 1 (3) & - & $2(6)$ & Medical therapy & 2 \\
\hline Pulmonary embolism & $1(1)$ & - & - & - & $1(3)$ & Medical therapy & 4 \\
\hline Myocardial infarction & $1(1)$ & - & $1(3)$ & - & - & Medical therapy & 4 \\
\hline Ureteral injury & $1(1)$ & - & $1(3)$ & - & - & Ureteral reimplantation & 3 \\
\hline
\end{tabular}

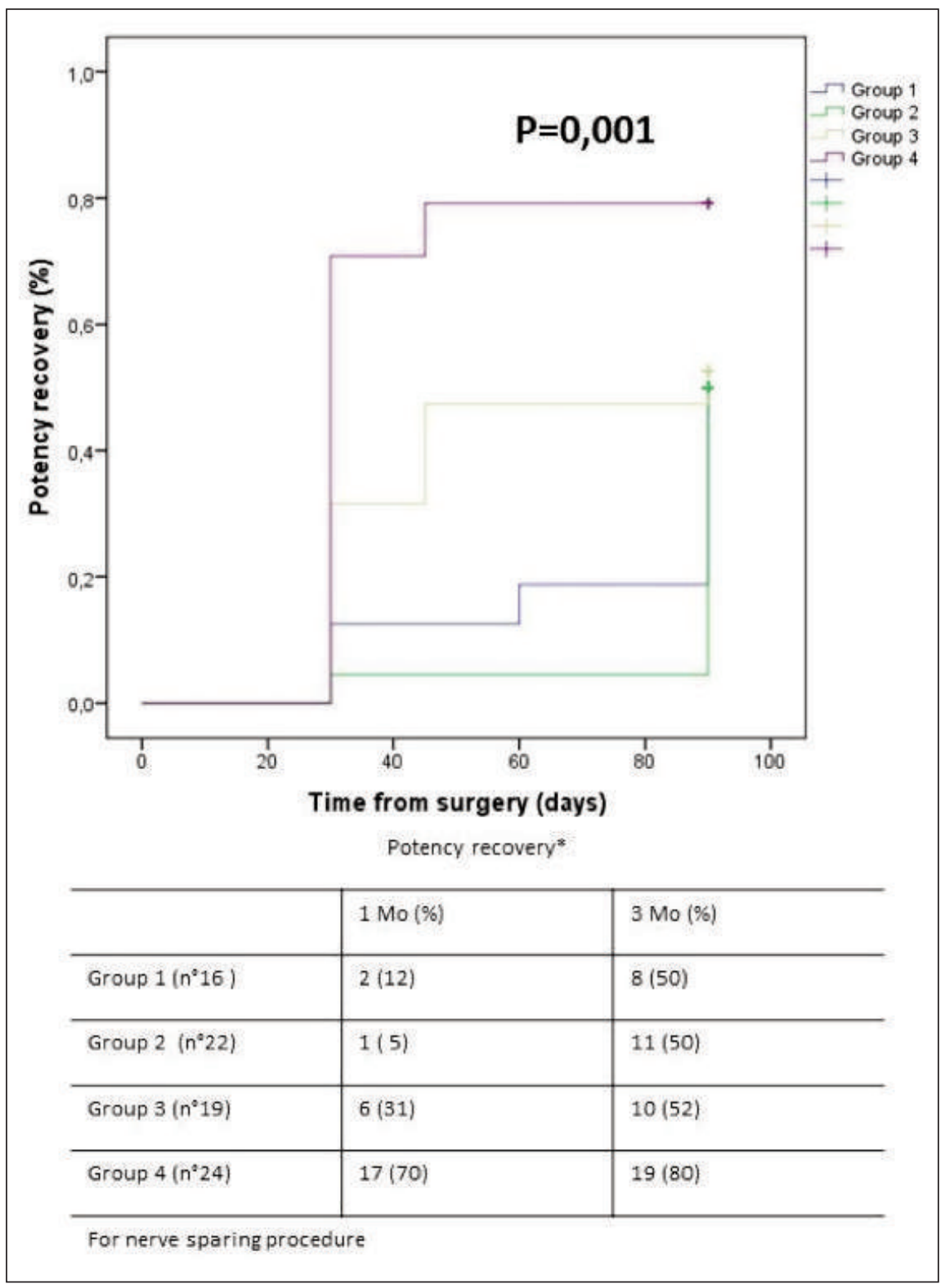

I-II) such as anaemia (31\%), fever (26\%) and lymphocele (21\%). No statistical differences were found in terms of complications between the four groups.

The overall continence rate at 1 and 3 months was $74 \%$ and $87 \%$ respectively (Table 2). Figure 1 depicts the urinary continence recovery rates after stratifying according to the four groups, 1 month and 3 months after surgery. We found a significant improvement in continence rate throughout the four groups $(\mathrm{p}=$ 0.04). All patients in the fourth group were continent 3 months after surgery.

Considering those patients submitted to nerve-sparing procedure, the median IIEF-5 was 18 and we found a significant increase in potency recovery over the four groups $(\mathrm{p}=0.04)$. Figure 2 shows the potency recovery rate after stratifying according to the four groups. The sexual function recovery rate rises gradually during the first three groups, however the last 30 procedures revealed significantly higher potency recovery rate up to $80 \%, 3$ months after surgery as compared to previous cases.

\section{Figure 1.}

Time to potency recovery according to the four groups. 


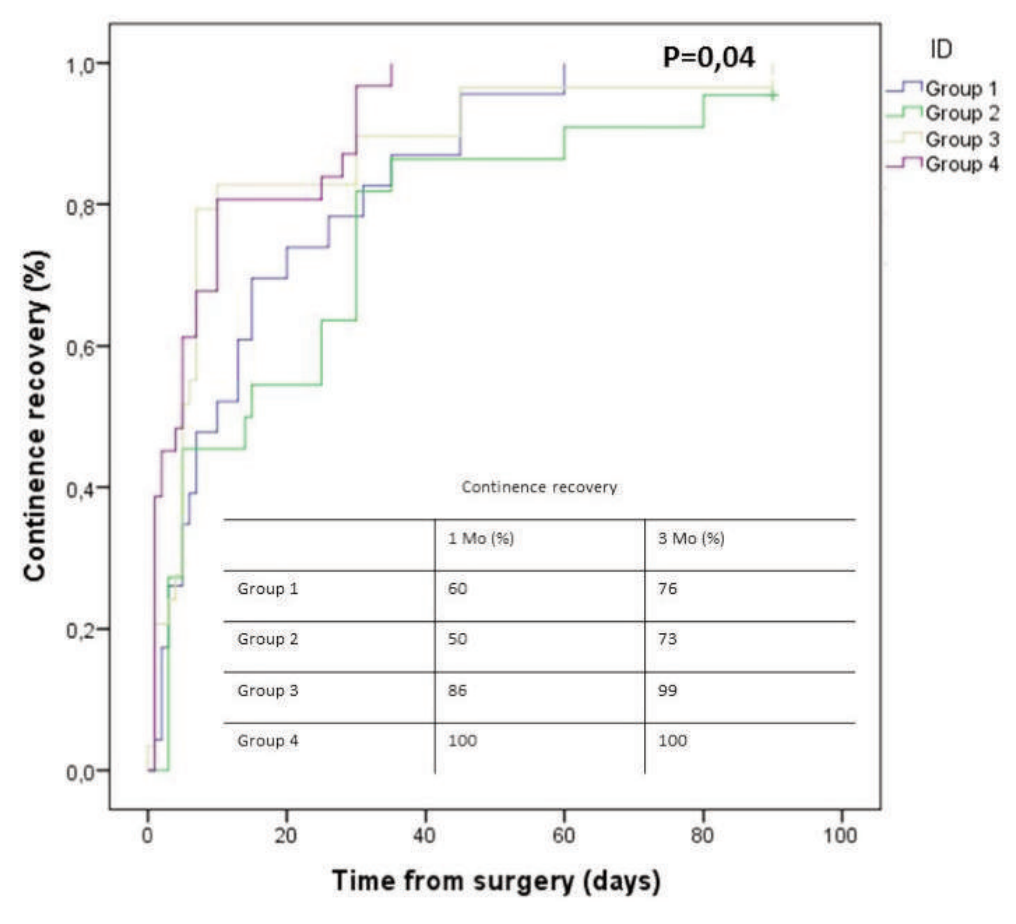

\section{Discussion}

The success of RALP is mainly due to the evidence that even inexperienced robotic surgeons could achieve high standards of surgery, with limited operative time, even in the early phase of the learning curve. Instead, complete urinary continence and erectile function recovery may require more surgical experience (18). To date, the number of RALP needed to achieve optimal functional outcomes such urinary continence and erectile function recovery is a hotly debated topic. Only limited studies show the functional outcomes during the learning curve $(9,12,19)$. Hence, the present study aimed to evaluate early functional and perioperative outcomes of an inexperienced robotic surgeon, after attending a structured modular training. Notably, in our report of the first 120 consecutive RALP, the intraoperative, post-operative and functional results were comparable to those previously reported in literature $(10,20)$. The overall operative time, the console time, and the PSM gradually decreased during the learning curve. After the first 30 cases the mean console time was comparable to those reported in hands of more experienced surgeons (237 min \pm 52) (21). Ahlering et al showed only 10-20 cases were required to achieve 4-h proficiency (7). However, Doumerc et al. demonstrated that at least 50 patients were needed to achieve a plateau of 200 minutes for an experienced "open-surgeon" who starts with robotic program, without attending a specific modular training (22). Another surrogate of proficiency in RALP is PSM rate, which mainly related to pathological stage and it's invariably higher in non-organ confined disease ( $\geq$ pT3a) (23). However, the incidence of PSM in organ confined (OC) prostate cancer is directly related to the quality of surgery (24). Indeed, in an initial report of 45 RALP, Ahlering et al. reported $14 \%$ of PSM in organ confined disease (7). Accordingly,
Figure 2.

Time to continence recovery according to the four groups.

in a recent meta-analysis, Novara et al. shows that PSM rate ranges from $0 \%$ to $20 \%$ and from 0 to $60 \%$ in OC and nonorgan confined disease, respectively (19). With regard of PSM rate, our findings underlines that a high quality of surgery was achieved even during the early phase of the learning curve. Indeed, overall PSM rate was $10 \%$ and $40 \%$ in OC and non-organ confined disease, respectively. Moreover, the PSM rate of OC disease decreased from 16\% among the initial 30 cases, to $4 \%$ in the latter 30 cases. Furthermore, we found no statistical difference with respect of the pathological stage between our groups, underlining that the decrease of PSM rate is mostly due to the improvement in robotic surgical skills. Alike surveillance protocols (25), minimally invasive surgery is aimed to reduce the potential sequelae, morbidity and post-operative complications. In this contest, mean post-operative complication rate for RALP is roughly $9 \%$ (21). However, complication rates reported during learning curve could be much higher, ranging from $1 \%$ to $40 \%$ (19). In the present series overall post-operative complication rate is $16 \%$, most of them (84\%) graded as minor complications (Clavien 1-2). In our experience the most severe complication was a ureteral injury which required a ureteral reimplantation. Notably, complication rates decreased from $30 \%$ in the first group to $13 \%$ in the last 30 procedures. This data are consistent with previous reported in literature, underlining that 20-30 cases may be need for a surgeon to overcome the "basic" learning curve. Lavery et al. identified an "advanced learning curve" in RALP, concerning urinary continence, erectile function recovery and PSM rate.

They concluded that 100-300 cases are needed to overcome this steeper learning curve (11). This is related to the relatively high level of difficulty in performing the anastomosis and the optimal compromise between neurovascular bundle preservation and the achievement of negative surgical margins. Some results of our study are noteworthy. First, despite our limited experience in robotic surgery and the short follow-up (3 months), we report optimal functional outcomes even in the early phase of the learning curve. Second, potency recovery raises exponentially throughout the four groups. In the latter group, $80 \%$ of patients undergoing nerve sparing procedures, recovered the preoperative erectile function 3 months after surgery. A wide variability of 3-months potency recovery is reported in literature, ranging from $32 \%$ to $68 \%(18,26)$. This could be explained by the several clinical predictors of potency recovery such as age, BMI, baseline IIEF score, nerve sparing technique and CCI (26). 
Third, in our series early ( 3 months) continence recovery rate, increases during the learning curve, particularly after the first 60 cases, reaching 99\% and 100\% in Group 3 and Group 4, respectively. Similarly to erectile function recovery, also urinary continence recovery, according to the definition of no-pad, is strongly influenced by age at surgery, prostate volume, BMI, and surgical technique $(10,27)$. As consequence, more controversial is the impact of surgeon experience and learning curve on the prevalence of urinary incontinence after RALP (10). Samadi et al. reported a significant increase of the continence rate after 500 cases (28); conversely excellent results were also reported in several clinical series including 100-200 cases $(5,22,28)$. Notably, no differences were found in terms of age at surgery, baseline IIEF score, CCI, and nerve sparing technique, between the four groups. This underlines that urinary continence and potency recovery are mostly due to improvement in robotic skills and almost 90 cases are needed to master anastomosis and nerve sparing procedure. Despite several strengths, our study has several limitations. First, this study only address perioperative outcomes at short term follow up. Second, the number of enrolled patients is limited, and could underestimate the main outcomes. Third, the great part of patients enrolled revealed low to intermediate risk PCa, since represent a learning curve cohort: it could influence our analysis and it could be not representative of learning curve in different population with higher proportion of high risk disease. Fourth, the main surgeon is a robotic naive surgeon experienced in open surgery but with limited skills in laparoscopic surgery. Indeed, the learning curve could be affected by previous surgical background and our data are not exportable to robot naive surgeons with pure laparoscopic experience.

\section{Conclusions}

In the present series, optimal perioperative and functional outcomes have been attained since early phase of the learning curve after an intensive structured modular training and only 90 consecutive procedures seem needed in order to achieve optimal urinary continence and erectile function recovery.

Our data suggest that an intensive structured modular training within RALP allows robotic naive surgeons to achieve optimal perioperative and functional outcomes since the early phase of the learning curve Indeed, after attending a structured modular training, 20-30 cases are sufficient to shorten operative time and lowering the complication rate.

\section{REFERENCES}

1. Ferlay J, et al. Cancer incidence and mortality worldwide: sources, methods and major patterns in GLOBOCAN 2012. Int J Cancer. 2015; 136:E359.

2. Heidenreich A, Bellmunt J, Bolla $M$, et al. EAU guidelines on prostate cancer. Part 1: screening, diagnosis, and treatment of clinically localised disease. Eur Urol. 2011; 59:61-71.

3. Walsh PC, Partin AW, Epstein JI. Cancer control and quality of life following anatomical radical retropubic prostatectomy: results at 10 years. J Urol. 1994; 152:1831-6.

4. Badani KK, Kaul S, Menon M. Evolution of robotic radical prostatectomy: assessment after 2766 procedures. Cancer. 2007; 110:1951-8

5. Ficarra $V$, Novara $G$, Rosen $R$, et al. Systematic review and metaanalysis of studies reporting urinary continence recovery after robot-assisted radical prostatectomy. Eur Urol. 2012; 62:405-17.

6. Ficarra $V$, Novara $G$, Ahlering $T$, et al. Systematic review and meta-analysis of studies reporting potency rates after robot-assisted radical prostatectomy. Eur Urol. 2012; 62:418-30.

7. Ahlering TE, Skarecky D, Lee D, Clayman RV. Successful transfer of open surgical skills to a laparoscopic environment using a robotic interface: initial experience with laparoscopic radical prostatectomy. J Urol. 2003; 170:1738-41.

8. Smith Jr JA. Robotically assisted laparoscopic prostatectomy: an assessment of its contemporary role in the surgical management of localized prostate cancer. Am J Surg. 2004; 188:63S-67S.

9. Patel VR, Tully AS, Holmes R, Lindsay J. Robotic radical prostatectomy in the community setting - the learning curve and beyond: initial 200 cases. J Urol. 2005; 174:269-72.

10. Young Hwii Ko, Jeong Hyeon Ban, Seok Ho Kang. Does robotassisted laparoscopic radical prostatectomy enable to obtain adequate oncological and functional outcomes during the learning curve? From the Korean experience. AJA. 2009; 167-175.

11. Hugh J. Lavery, David B. Samadi, Rahul Thaly. The advanced learning curve in robotic prostatectomy: a multi-institutional survey. J Robotic Surg. 2009; 3:165-169.

12. Hashimoto T, Yoshioka K, Gondo T, et al. Learning curve and perioperative outcomes of robot-assisted radical prostatectomy in 200 initial Japanese cases by a single surgeon. J Endourol. 2013; 27:1218-23.

13. Volpe A, Ahmed K, Dasgupta P, et al. Pilot validation study of the European Association of Urology robotic training curriculum. Eur Urol. 2015; 68:292-9.

14. Lovegrove C, Novara G, Mottrie A, et al. Structured and modular training pathway for robot-assisted radical prostatectomy (RARP): validation of the RARP assessment core and learning curve assessment. Eur Urol. 2016; 69:526-35.

15. Sood A, Jeong W, Ahlawat R, et al. Robotic surgical skill acquisition: What one needs to know? J Minim Access Surg. 2015; 11:10-5.

16. Mottrie A, Van Migem P, De Naeyer G, et al. Robot-assisted laparoscopic radical prostatectomy: oncologic and functional results of 184 cases. Eur Urol. 2007; 52:746-50

17. Clavien PA, Barkun J, de Oliveira ML, et al. The Clavien-Dindo classification of surgical complications: five-year experience. Ann Surg. 2009; 250:187-96.

18. Schiavina $R$, Borghesi $M$, Dababneh $H$, et al. Survival, Continence and Potency (SCP) recovery after radical retropubic prostatectomy: a long-term combined evaluation of surgical outcomes. Eur J Surg Oncol. 2014; 40:1716-23.

19. Artibani W, Fracalanza S, Cavalleri S. Learning curve and preliminary experience with da Vinci-assisted laparoscopic radical prostatectomy Urol Int. 2008; 80:237-44.

20. Novara G, Ficarra V, Mocellin S. Systematic review and metaanalysis of studies reporting oncologic outcome after robot-assisted radical prostatectomy. Eur Urol. 2012; 62:382-404. 
21. Novara G, Ficarra V, Rosen RC. Systematic review and metaanalysis of perioperative outcomes and complications after robotassisted radical prostatectomy. Eur Urol. 2012; 62:431-52.

22. Doumerc N, Yuen C, Savdie R, et al. Should experienced open prostatic surgeons convert to robotic surgery? The real learning curve for one surgeon over 3 years. BJU Int. 2010; 106:378-84.

23. Schiavina R, Borghesi M, Fiorentino $M$, et al. Identification of prostate cancer risk categories according to surgical margins status, pathological stage and Gleason score. Int J Urol. 2013; 20:1097-103.

24. Heidenreich A. Quality control in radical (laparoscopic) prostatectomy. Eur Urol. 2006; 49:767-768.

25. Brunocilla E, Borghesi M, Schiavina R, et al. Small renal masses initially managed using active surveillance: results from a retro- spective study with long-term follow-up. Clin Genitourin Cancer. 2014; 12:178-81.

26. Eastham JA. Robotic-assisted prostatectomy: Is there truth in advertising? Eur Urol. 2008; 54:720-2.

27. Brunocilla E, Schiavina R, Pultrone CV, et al. Preservation of the smooth muscular internal (vesical) sphincter and of the proximal urethra for the early recovery of urinary continence after retropubic radical prostatectomy: a prospective case-control study. Int J Urol. 2014; 21:157-62.

28. Samadi DB, Muntner P, Nabizada-Pace F. Improvements in robot-assisted prostatectomy: the effect of surgeon experience and technical changes on oncologic and functional outcomes. J Endourol. 2010; 24:1105-10.

\section{Correspondence}

Schiavina Riccardo, MD

rschiavina@yahoo.it

Borghesi Marc, MD

mark.borghesil@gmail.com

Dababneh Hussam, MD

drdababneh@gmail.com

Rossi Martina Sofia, MD

martinasofia.rossi@gmail.com

Pultrone Cristian Vincenzo, MD

cristian.pultrone@gmail.com

Vagnoni Valerio, MD

vagno07@libero.it

Chessa Francesco, MD (Corresponding Author)

francesco.chessa2@studio.unibo.it

Bianchi Lorenzo, MD

lorenzo.bianchi3@studio.unibo.it

Brunocilla Eugenio, MD

eugenio.brunocilla@unibo.itUniversity of Bologna, S. Orsola-Malpighi

Hospital, Dept. of Urology, Bologna

via Palagi 9 40134, Bologna, Italy

Porreca Angelo, MD

angeloporreca@gmail.com

Policlinico Di Abano, Dept. of Urology, Abano Terme, Italy

Mottrie Alexandre, MD

a.mottrie@telenet.be

OLV Robotic Surgery Institute, Aalst, Belgium 